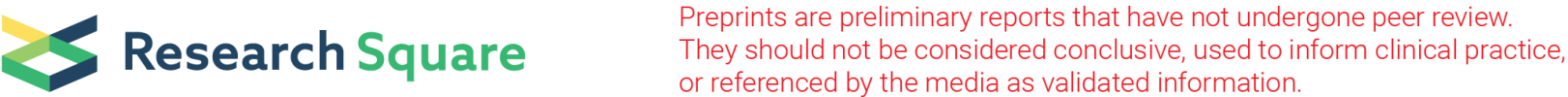

\section{Nitrogen and phosphorus emission to water in agricultural crop - animal systems and driving forces in Hainan Island, China}

\section{Xu Liang}

Hainan University

Yanhu He

Guangdong University of Technology

Lirong Zhu

Hainan University

Shijie Fan

Hainan University

Yi Zou

Hainan University

Changqing Ye ( $\sim$ yechangqing2001@hotmail.com )

Hainan University

\section{Research Article}

Keywords: nitrogen, phosphorus, Hainan Island, agriculture, high resolution, driving forces

Posted Date: January 21st, 2022

DOI: https://doi.org/10.21203/rs.3.rs-1162971/v1

License: (c) (i) This work is licensed under a Creative Commons Attribution 4.0 International License.

Read Full License 


\section{Abstract}

Identifying the spatial characteristics of nitrogen $(\mathrm{N})$ and phosphorus $(\mathrm{P})$ emission from agriculture to water bodies and quantifying effect factors are critical to explore the mitigation options. A high-resolution NUFER (Nutrient Flow in food chains, Environment and Resources) model based on geology, meteorology, land use data, statistical data, and field investigation was used to quantify the spatial characteristics of N/P emissions in Hainan Island, China, driving forces was analyzed and effective measures to reduce emissions in 2035 was explored with scenario analysis. Overall, $98 \mathrm{Gg} \mathrm{N}$ from agriculture entered water bodies in 2018 , of which the crop system contributed $70 \% ; 15 \mathrm{Gg}$ P entered water bodies, animal system contributed $78 \%$. Nitrate $\left(\mathrm{NO}_{-3}\right)$ leaching $(65 \%)$ and direct discharge of animal manure $(69 \%)$ accounted for the most to the $\mathrm{N}$ and $\mathrm{P}$ emissions, respectively. $89 \%$ of $\mathrm{N}$ and $92 \%$ of $\mathrm{P}$ emissions occurred in plain areas. Spatial overlay analysis showed that high $\mathrm{N}$ and $\mathrm{P}$ emissions mainly concentrated in the western and northeastern plain areas. At the sub-basin scale, Nandu River was the largest basin of agricultural N/P emissions, accounting for more than $20 \%$ of the total emissions. Our correlation analysis showed that N/P emissions were significantly correlated to natural (such as elevation, slope and soil texture) and anthropogenic (e.g., rural income, population density, planting structure and livestock density) factors. We further analyzed the emissions of N/P can be reduced by $71 \mathrm{Gg}$ and $14 \mathrm{Gg}$ by 2035 respectively, via reducing food chain waste and consumption, importing more food and improving production efficiency, especially prohibiting the direct discharge of livestock manure. Our research quantified agricultural $\mathrm{N}$ and $\mathrm{P}$ emissions to the water bodies in a high-resolution context and explored the most effective options for reduction of agricultural non-point source pollution (ANPS) emissions at the island scale.

\section{Introduction}

Nutrient elements nitrogen $(\mathrm{N})$ and phosphorus $(\mathrm{P})$ are essential for agricultural production and human health(Galloway et al., 2008). The expansion of China's population in the past few decades has greatly increased human demand for agricultural products. Along with the substantial increase in the scale of agricultural production is the massive input in fertilizers and fodder(Hou et al., 2018). China has become the world's largest fertilizer consumer and livestock product producer(Bai et al., 2016; Chadwick et al., 2015). Excessive emissions of $\mathrm{N}$ and $\mathrm{P}$ have caused varying degrees of pollution to natural ecosystems such as water bodies, soil and atmosphere, especially the eutrophication risks in coastal areas(Wang et al., 2021). The agricultural system was currently the primary source of N/P emission(Hou et al., 2018; Yu et al., 2019). Excessive emission of N/P nutrients from farmland and pasture was considered to be the leading cause for the global eutrophication of coasts and oceans from the last century to the present(Vigouroux et al., 2021). The nutrient level from agricultural exports was much higher than that of land-use types such as forests and grasslands(Rodríguez-Gallego et al., 2017). According to the second pollution source survey report in China(MEEP, 2020), $47 \%$ of $\mathrm{N}$ and $68 \%$ of $\mathrm{P}$ entering the water bodies came from agriculture, with $51 \%$ and $36 \%$ emissions from crop systems, while the losses from the animal system accounted for $42 \%$ and $57 \%$ respectively(MEEP, 2020). 
Excessive input of N/P was a critical aspect of the eutrophication risk of water bodies. On the other hand, the agricultural utilization efficiency of N/P in both crop and animal systems was low at present, compared to the United States, the European Union and Japan(Bai et al., 2016; Ma et al., 2012; Zhang et al., 2021). This made a large amount of nutrients unable to be used by agriculture, thus being lost to the environment. Hainan Island is China' the only tropical provincial island, with a complete agricultural industry chain and rapid development. Under the background that Hainan Island will be built as a Pilot Free Trade Zone, the increase in population has led to the rapid growth of agriculture, and the nutrients lost caused by agriculture in the future may lead to a more severe risk of eutrophication(Sun et al., 2020). Eutrophication has occurred in different coasts of Hainan Island in recent years(Herbeck et al., 2013; Huang et al., 2017; Zhang et al., 2020a; Zhang et al., 2020b), and it has become one of the regions with the highest risk of eutrophication in the world(Yang et al., 2016).

Large-scale experimental samples were generally lacking in agricultural non-point source pollution(ANPS), and local-scale experiments were difficult to extend to the macro-regional level(Kaushal et al., 2011). Thus, obtaining high resolution spatial characteristics of $\mathrm{N}$ and $\mathrm{P}$ losses at the macro level became a critical approach in agricultural nutrient emission study. Large number of factors such as natural (temperature, precipitation, elevation, slope, soil texture) and anthropogenic factors (rural income, population density, planting structure, livestock density) influenced the agricultural $\mathrm{N}$ and $\mathrm{P}$ emissions(Gu et al., 2013; Zhao et al., 2019). The agricultural production patterns of plain and hill areas also have great differences. Different emission characteristics have corresponding sensitivities to various driving factors. Exploring and quantifying natural and anthropogenic factors that generate changes in N/P emissions is essential to determine effective strategies for reducing of excessive N/P emissions to water.

Given this, many hydrological simulation models have been applied to investigate the characteristics of ANPS, such as SWAT and AnnAGNPS (Cheng et al., 2021; Li et al., 2015). However, the terrain of Hainan Island was radial, and these basins are independent. Therefore, it was impractical to study all the basins of Hainan Island as a system. And these models required a large number of measured data and information, that were difficult to obtain at a provincial level of tropical islands, which limits their application(Zhao et al., 2019). The output coefficient method provides researchers with an approach to determine control elements without monitoring the water quality of the basin. The nutrient output model is a basin-scale model that could simulate nutrient input and output with less data, and can be used to estimate the $\mathrm{N}$ and $\mathrm{P}$ emission of global rivers or oceans. Recently, the NUFER (Nutrient Flow in food chains, Environment and Resources) model has been used to measure migration process of $\mathrm{N}$ and $\mathrm{P}$ in the complete food chain, it can be used to estimate $\mathrm{N}$ and $\mathrm{P}$ losses in each step of the food chain(Bai et al., 2016; Ma et al., 2010). So far, the spatial pattern of $\mathrm{N}$ and $\mathrm{P}$ emissions to water bodies from agriculture has not been systematically quantified in Hainan Island, especially under high resolution. The effect factors of these spatial characteristic have not yet been studied, which limited the potential of effective mitigation strategies in the future.

The primary purposes of this study were to quantify agricultural N/P emissions to water on the spatial scale at higher resolution, analyze the factors impacting of N/P emission and explore mitigation 
strategies in Hainan Island. To achieve these goals, we first collected statistics on Hainan Island and selected the parameters of the developed NUFER model applicable to Hainan Island. Second, we determined the distribution coefficients of $\mathrm{N}$ and $\mathrm{P}$ loss based on the land use data in 2018. Third, we explored the driving forces of variations in $\mathrm{N}$ and $\mathrm{P}$ emission to water considering both natural and anthropogenic factors through linear regression analysis. Finally, we simulated several scenarios to explore mitigation options and potential in Hainan Island. This study produced high resolution map of agricultural N/P emissions to water that can be used to explore driving forces and model reduction option at the island scale.

\section{Materials And Methods \\ 2.1 Study area}

Hainan Island is China's second largest island and the only province in China that is entirely in the tropics. It is located on the north of the South China Sea and faces Leizhou Peninsula across the sea through the Qiongzhou Strait(Lu et al., 2021). Hainan Island covers an area of approximately $3.39 \times 10^{4} \mathrm{~km}^{2}$ and owns $42.3 \%$ of the country's sea area(Zhang et al., 2013). Affected by the monsoon climate, the rainy season in Hainan Island is from May to September, and the dry season is from October to April. The annual average temperature is $22.8-25.8^{\circ} \mathrm{C}$, the annual average precipitation ranges from 961 to $2439 \mathrm{~mm}$ (Fang et al., 2020; Zhang et al., 2020b). The terrain of Hainan Island is radial, with mountainous areas in the middle and plains all around. Hainan Island is usually divided into 26 sub-basins, of which the top three basins are Nandu River, Changhua River, and Wanquan River. The agricultural development foundation of Hainan Province is relatively behindhand, but the proportion of agricultural output value has always occupied the first place in China (National Bureau of Statistics). Hainan Island is mainly planted with tropical economic crops and fruits. The wastewater produced in the basin basically flows into the ocean. According to statistics in 2019, eutrophication of the coast of Hainan Island was $195 \mathrm{~km}^{2}$.

\subsection{Estimation of N/P emission to water bodies from agriculture}

$\mathrm{N} / \mathrm{P}$ emission from agriculture to water bodies includes emission from crop systems and animal system. The crop system enters the water bodies via leaching, runoff, and erosion, and the animal system enters the water via the leaching and direct discharge in the livestock management chain. An improved high resolution-based NUFER model with local natural parameters were used to estimate N/P emission. The NUFER model follows the principle of mass conservation and can be used to estimate the nutrients input, migration, transformation and output of different crops and animal categories(Bai et al., 2016; Ma et al., 2010; Velthof et al., 2009; Zhao et al., 2019). Below are the formulas of N/P losses in crop systems:

$$
N, P_{\text {erosion }}=N, P_{\text {topsoil }} \times L F_{\text {erosion }, \max } \times f p \times \min (f l u, f r c, f s)
$$




$$
N, P_{\text {runoff }}=N, P_{\text {application }} \times L F_{\text {runoff, } \max } \times f l u \times \min (f p, f r C, f s)
$$

$$
N, P_{\text {leaching }}=E, P_{\text {surplus }} \times L F_{\text {leaching }, \max } \times f l u \times \min (f p, f r C, f t, f C)
$$

3

where Eqs (1) - (3) are $\mathrm{N}$ and $\mathrm{P}$ erosion, runoff, leaching from crop system, respectively. $N, P_{\text {erosion, }}$ $N, P_{\text {runoff }} N, P_{\text {leaching }}$ are the $\mathrm{N}$ and $\mathrm{P}$ emission to water bodies via soil erosion, surface runoff and leaching, respectively, unit: t; $N, P_{\text {topsoir }} N, P_{\text {application }}, N, P_{\text {surplus }}$ are the $\mathrm{N}$ and $\mathrm{P}$ content in the soil surface, applied in arable land and surplus in soil; $L F_{\text {erosion,max }} L F_{\text {runoff,max }} L F_{\text {leaching,max }}$ are the maximum fraction of soil erosion, surface runoff and leaching, respectively; $f p, f l u, f r c, f s, f t, f c$ are the reduction coefficients of precipitation, land use, soil depth, soil type, temperature and soil organic matter content, respectively. The detail of parameters and specific values used can be seen in the Supplemental Information (SI).

For crop system, we collected agricultural data (Table S2) at the town level in 2018 and calculated the $N, P_{\text {topsoil }}, N, P_{\text {application }} N, P_{\text {surplusi }}$, then we used the spatial data(Fig. S1) to make the distribution of N/P reduction coefficients (1) - (3) map respectively (Fig. 1). Finally, $N, P_{\text {topsoir }} N, P_{\text {application }}, N, P_{\text {surplus }}$ were evenly allocated to the arable land and economic forest of each county, according to the land use data with a resolution of $30 \mathrm{~m} \times 30 \mathrm{~m}$.

For animal system, N/P were discharged to water via leaching and direct discharge from livestock management chain (including housing, storage and treatment stages). We first calculated the total N/P emissions by multiplying the excretion rate (Table S3) with the number of livestock in different animal categories, then calculated by multiplying the respective the proportion of direct discharge or leaching with total emission in the management chain of animal obtained from the investigation. Finally, the N/P emission in the animal system were evenly distributed to the rural settlements of each town, premising all the manure that can be used to return to the farmland and will be used for the cultivated land of each town. $\mathrm{N}$ and $\mathrm{P}$ emissions from animal system were also evenly allocated to the rural settlement in housing, manure storage, and treatment stages (Zhao et al., 2019). To reduce the uncertainty of the results, we further proceeded an overlay analysis on N/P emission and aggregated the results into $1 \mathrm{~km} \times$ $1 \mathrm{~km}$.

\subsection{Data collection}

Data used in this study include statistics, investigation data, parameters from the literatures, and spatial data. The statistical data came from the statistical yearbook of counties and towns, including the crop planting area, sowing amount, livestock number, chemical fertilizer application, and population in 2018. Then, we estimated organic fertilizer application, straw return rate, return rate of manure to field and fertilizer management methods of filed investigation data via systematic farm investigation covering 106 individual farms in 18 counties and 195 typical towns in Hainan Island. These investigation content including crop fertilization, crop product/straw destination, planting and management methods, 
information of livestock houses, manure storage, and treatment with farmers; N/P content of crops and animals was obtained from literatures(Bai et al., 2016; Ma et al., 2010). The spatial data of land use, soil type, soil texture, precipitation, temperature, elevation, income and population density from the Resource and Environment Science and Data Center (http://www.resdc.cn). The spatial data of precipitation was derived from monthly data of 88 stations in Hainan Province, and the inverse distance weighting method was used to interpolate the values in ArcGIS.

\subsection{Driving forces analysis}

The losses of agricultural N/P were mainly related to both natural and anthropogenic factors. In this study, five natural factors, namely temperature, precipitation, elevation, slope, and soil texture, and two anthropogenic factors, rural income and population density, were determined based on the data for towns. We further explored the relationship between planting structure, livestock density, slope, soil texture and the output of N/P in plain and hill areas, respectively.

In this study, the township boundary map (excluding Sansha City) was used, and the geographic coordinate system was set to WGS1984 in ArcGIS10.2.

Many models can measure the relationship between impact factors and variables, such as linear and nonlinear, univariate and multivariate regression models. In this study, the relationship between N/P and agricultural losses was generally described as a simple linear, so univariate linear regression method was used for analysis(Gu et al., 2013). SPSS (Statistical Package for the Social Science) statistical software (v22.0) was used for regression and statistical analysis, and the significance levels were set at $P<0.05$.

\subsection{Scenarios in 2035}

In the macroscopic model of nutrient management, different scenarios were usually adopted to achieve goals. China's goal of zero growth of fertilizers and FAO's predictions for animal products were considered, and five scenarios were set up to simulate the potential of animal system species to reduce N/P losses in 2035, used by Bai(Bai et al., 2016). Zhao(Zhao et al., 2019) combined the crop system and further explored the future agricultural management of N/P in terms of food consumption, import, and production efficiency. In this study, six scenarios were set up to analyze the agricultural N/P management of Hainan Island in 2035:

(1) SO: BAU (Business As Usual). The number of animal products is based on the linear extrapolation predicted by FAO and the population growth rate and the growth rate of crops and livestock products under the 2035 development goal of Hainan Free Trade Port. In this case, we assume that the increase in demand for livestock products will occurred in animal system. System production efficiency, feed and fertilizer management practices are the same as in 2018.

(2) S1: Food chain waste will be reduced, so crop yields, meat and fertilizer consumption will be reduced compared to SO. In addition, the recommendations in the Chinese Dietary Guidelines (2016) will be adopted. 
(3) S2: Importing More Food (IMF). The food self-sufficiency rate is maintained at $90 \%$, and the output of local crops, livestock and poultry will be reduced.

(4) S3: Producing More and Better (PMB). The production efficiency of rice, vegetables, and fruits will increase, hence the quantity of chemical fertilizers has been reduced accordingly. In addition, the direct discharge of livestock manure will be replaced completely by 2035, manure returned to the field will be used to the maximum extent.

(5) S4: Combination of $S 1$ and $S 3$

(6) S5: Combination of $S 1-S 3$

\section{Results}

\subsection{Agricultural N/P emission to water in Hainan Island}

The estimated total $\mathrm{N}$ emission to water from crop - animal systems in Hainan Island was $98 \mathrm{Gg} \mathrm{yr}^{-1}$ in 2018, with 70\% from crop system and 30\% from animal system (Fig. 2). The leaching loss from crop system was the largest way (65\%), followed by direct discharge in livestock manure to water bodies (16\%). Two large sources were $N$ fertilizer and fodder, which contributed $53 \%$ and $36 \%$ to total $N$ input in crop and animal system, respectively. The total P emission to water from crop and animal system was 15 $\mathrm{Gg} \mathrm{yr}^{-1}$ in 2018 , of which $15 \%$ was from crop system and $85 \%$ came from animal system (Fig. 2). The largest loss way was direct discharge of livestock manure, which contributed $69 \%$. P fertilizer and fodder were two large sources, which accounting for $63 \%$ and $33 \%$ to total P input in crop and animal system, respectively.

From a spatial perspective, there were great differences in $\mathrm{N}$ and $\mathrm{P}$ emissions from agriculture (Figs. 3 and 4). The $\mathrm{N}$ emission to water in plain and hill areas contributed $89 \%$ and $11 \%$, respectively. The highest $\mathrm{N}$ emission intensity occurred in areas with concentrated livestock industry and coastal plains.

From the perspective of sub-basins, the highest average $\mathrm{N}$ emission intensity is $8 \mathrm{t} \mathrm{km}^{-2}$. Nandu river was the largest basin of agricultural $\mathrm{N}$ emissions, which contributed $20 \%$ of total $\mathrm{N}$ emissions to water. Jiuqu river was the basin with the highest $\mathrm{N}$ emission intensity, which reached $12.3 \mathrm{t} \mathrm{km}^{-2} \mathrm{yr}^{-1}$ (Figs. 5a, b). The plain area contributed $92 \%$ of total $\mathrm{P}$ emission to water. Different from the spatial pattern of $\mathrm{N}$, the highest density of $\mathrm{P}$ was concentrated in the rural settlement and the plains near the central and northern regions, rather than near the coast, which reached $0.9 \mathrm{t} \mathrm{km}^{-2}$. Nandu river basin contributed $22 \%$ to agricultural $\mathrm{P}$ emissions and Shibi river has highest $\mathrm{P}$ emission intensity $\left(4.2 \mathrm{t} \mathrm{km}^{-2} \mathrm{yr}^{-1}\right)$.

Spatial overlay analysis showed that high $\mathrm{N}$ and $\mathrm{P}$ emissions mainly concentrated in the western, northern and northeastern plain areas of Hainan Island (Fig. 6).

\subsection{Driving forces of agricultural N/P emission to water}


Statistical analysis showed that the N/P emission had different correlations with natural and anthropogenic factors (Fig. 7). Both $\mathrm{N}$ and $\mathrm{P}$ emissions were negatively related to elevation and slope, while positively related to share of loam land and rural income, indicating high N/P emission was more likely to occur in rural areas on the plains with loam land.

Both $\mathrm{N}$ and $\mathrm{P}$ emissions were influenced by natural and anthropogenic factors to varying extent in plain and hill areas (Fig. 8 and 9). For N, the share of rice and vegetable, the density of pig, cattle and poultry was positively related to $\mathrm{N}$ emission, and negatively related with slope, which was more obvious in hill areas. In plain areas, $\mathrm{N}$ emission was positively correlated with the share of rice, vegetable and loam land. For $\mathrm{P}$, slope, share of rice and loam land, density of pig, cattle and poultry were positively correlated with $\mathrm{P}$ emission. That indicated anthropogenic factors have similar effects on $\mathrm{N}$ and $\mathrm{P}$ emissions, while natural factors have different effects on N/P emission.

\subsection{N/P emission in 2035 under different scenarios}

In general, as the population increases, N/P emission will increase from 2018 to 2035, due to the increasing demand for livestock products. However, if effective management measures are adopted, N/P emission can be maintained at a relatively low level in the future (Fig. 2).

Under the BAU (S1) scenario, the island's $\mathrm{N}$ and $\mathrm{P}$ emissions will increase by $15 \%$ and $17 \%$, respectively. Nitrate $\left(\mathrm{NO}_{3-}\right)$ leaching will increase by $15 \%$, and the $\mathrm{P}$ direct discharge of livestock manure will increase by $12 \%$ (Fig. 2 ).

Reducing food loss and optimization on human diet (CWL, S2), increasing food imports (IMF, S3) and improving production efficiency (PMB, S4) would have effect on reducing N/P emission in 2035, compared to S1. Under the PMB (S4) scenario, the N/P direct discharge of livestock manure will completely disappear in 2030 , hence this scenario is the most effective measure to reduce emissions, compared to CWL and IMF scenarios (Fig. 2).

If the above-mentioned policies were combined, nutrients emission will remain at a lower level in the future. For instance, at sub-basins scale, the average emission densities of $\mathrm{N}$ and $\mathrm{P}$ would be lower than $4.3 \mathrm{t} \mathrm{km}^{-2}$ and $0.2 \mathrm{t} \mathrm{km}^{-2}$ respectively under $\mathrm{PMB}+\mathrm{CWL}$ scenario (Figs. $5 \mathrm{c}, \mathrm{d}$ ). Under the $S 5$ (CWL+IMF+PMB) scenario, total $N$ and $P$ emissions to water bodies will be reduced by $71 \mathrm{Gg} \mathrm{N}$ and $14 \mathrm{Gg}$ P, respectively in 2035(Fig. 2).

\section{Discussion}

We quantified the characteristic of $\mathrm{N}$ and $\mathrm{P}$ emissions from agriculture in different basins of Hainan Island in the tropical areas from 2018 to 2035 under the context of high resolution, analyzed driving forces, and then evaluated management measures under different scenarios in the future. In $2018, \mathrm{~N}$ leaching in crop system was the main way of agricultural $\mathrm{N}$ emissions, and the direct discharge of livestock manure of $\mathrm{P}$ was the main way of agricultural $\mathrm{P}$ emissions. Both natural and anthropogenic 
factors have impacts on $\mathrm{N}$ and $\mathrm{P}$ emissions to varying extent. In the future, a series of management measures, especially the complete replacement of direct discharge in animal system, are important measures to reduce N/P emission from agriculture.

\subsection{Uncertainty}

In this study, the uncertainty was mainly related to the sources of statistical data and the data obtained from field investigations. The source of statistical data refers to official publications from government departments. The data at county and town levels usually have an error of less than 10\%. Therefore, we used town-level data to calculate social-economic indicators. In our field investigation, part of the manure treatment methods (composting, returning to the field, direct discharge, biogas fermentation, etc.) were done via direct observation or consultation with farmers, which caused some errors. In order to reduce the uncertainty of the results, we aggregated $N$ and $P$ emissions into $1 \mathrm{~km} \times 1 \mathrm{~km}$ via overlay analysis to highlight the hot areas with high $\mathrm{N}$ and high $\mathrm{P}$ emissions.

Our estimation showed that the average $\mathrm{N}$ leaching of agriculture in Hainan Island was $5.02 \mathrm{t} \mathrm{km}^{-2} \mathrm{yr}^{-1}$, which was similar to that(4.63t km-2 $\mathrm{yr}-1)$ of estimated by Zhou (2011) in Hainan Island (Zhou, 2011), higher than that(3.76t km2 yr-1) of estimated by Yu (2019) in China(Yu et al., 2019), 3.1 times that(1.60t $\mathrm{km}^{-2} \mathrm{yr}^{-1}$ ) of the EU-27(Velthof et al., 2009). This result might be explained by the effect of different soil textures. In Hainan Island, $52 \%$ of the soil is sand land, which contributed the most to $\mathrm{N}$ leaching(Koops et al., 1996; Salm et al., 2007). For $P$ emissions from the crop system, our estimation showed that the $P$ loss rate in Hainan Island was $0.25 \mathrm{t} \mathrm{km} 2 \mathrm{yr}-1$, which is lower than that $\left(0.36 \mathrm{t} \mathrm{km}^{-2} \mathrm{yr}^{-1}\right)$ estimated by Zhou(Zhou, 2011), while slightly higher than the averages(0.21 t km-2 $\left.\mathrm{yr}^{-1}\right)$ reported in China(Han et al., 2021).

There were also some uncontrollable factors that can cause uncertainty in the results, such as changes $\mathrm{N}$ and $\mathrm{P}$ content in crop caused by changes in field fertilization or natural factors, and volatilization when livestock manure was returned to the field. Further survey combined with field experiments will better help the model obtain more accurate parameter information.

\subsection{Driving forces of agricultural N/P emission to water}

Considering the unique and complex topography of Hainan Island, N/P emission in agriculture was not only correlated with anthropogenic factors (planting structure, livestock density, rural income, population density), but also related to natural factors (elevation, slope, share of loam land).

In plain areas, $\mathrm{N}$ emissions were positively related to livestock density and negatively correlated with slope, which shows that agriculture production was mainly concentrated in flat plain areas. The emission of $\mathrm{P}$ was positively correlated with slope, which may be explained by soil erosion as the main pathway of $P$ loss in crop systems. The soil erosion effect of slope and $P$ emission has an obvious positive correlation (Remund et al., 2021; Yan and Gao, 2021). Our results showed that P emissions on the plains were positively correlated with the share of loam land, indicating that the loam land areas were more 
suitable for the development of agriculture, which was similar to the results of Zhao(2019)(Zhao et al., 2019).

However, there was currently no definitive way to accurately measure the characteristic of $\mathrm{N}$ and $\mathrm{P}$ loss from a macro level. The loss of $\mathrm{N}$ and $\mathrm{P}$ was not only related to the above factors, but also related to more microscopic factors such as soil depth, changes in the form of nutrients matters, and the migration and transformation of elements. In order to better explore the loss of agricultural nutrients at the macro level, considering the above levels will be the focus of future research.

\subsection{Potential risks of water resources and the significance of future management}

Our results showed that the average $\mathrm{N}$ leaching of Hainan Island was higher than the average of the previous study(Zhou, 2011), China(Yu et al., 2019) and 27-European countries(Velthof et al., 2009), which was potentially harmful to groundwater quality, especially in coastal zones that were vulnerable to seawater intrusion. Hainan Island has abundant rainfall and numerous typhoons, which will increase the rate of $\mathrm{P}$ loss(Yan and Gao, 2021). Therefore, if no measures are taken, the nutrients that enter the water body will eventually flow to the South China Sea, and will aggravate the future eutrophication risk in the coastal zone of Hainan Island.

Several scenarios clearly showed the potential for reduction of $\mathrm{N}$ and $\mathrm{P}$ emission with or without management measures. Reducing agricultural products waste and consumption, importing more agricultural products have a significant effect on the future reduction of $\mathrm{N}$ and $\mathrm{P}$. However, improving production efficiency and prohibiting the direct discharge of livestock manure were the most effective measures. The largest input source of $\mathrm{N}$ and $\mathrm{P}$ in farmland was chemical fertilizers. Therefore, it was necessary to explore and improve chemical fertilizer application technology under the premise of ensuring the stability of agricultural yield. Replacing chemical fertilizers with organic fertilizers was also an option.

Our results may be conservative. We did not consider pesticides due to its volatility. In order to realize the safety of agricultural water resources under the construction of the Hainan Free Trade Port, the government also needs to vigorously promote improvement measures, such as strengthening the infrastructure of irrigation (such as trickle irrigation) for saving water resource and reducing excessive application of chemical fertilizer, which can further reduce the loss of these emissions. Our research can provide better insights for reducing the eutrophication risk from agriculture.

\section{Conclusion}

We constructed a high-resolution NUFER model to quantify the spatial characteristics of $\mathrm{N}$ and $\mathrm{P}$ emissions of Hainan Island, analyzed the main influencing factors and proposed the corresponding mitigation options in Hainan Island. Overall, total $\mathrm{N}$ and $\mathrm{P}$ emissions to water from agriculture in 2018 was respectively $98 \mathrm{Gg} \mathrm{yr}^{-1}$ and $15 \mathrm{Gg} \mathrm{yr}^{-1}$ in Hainan Island. Nitrate $\left(\mathrm{NO}_{3-}\right)$ leaching (65\%) and direct 
discharge of livestock manure (69\%) contributed most emissions of $\mathrm{N}$ and $\mathrm{P}$, respectively. Emissions to water were significantly related to natural and anthropogenic factors. High density of $\mathrm{N}$ and $\mathrm{P}$ mainly concentrated in the plain areas. $\mathrm{N}$ and $\mathrm{P}$ emissions can be reduced by $71 \mathrm{Gg}$ and $14 \mathrm{Gg}$ in 2035 respectively, if reducing food chain waste and consumption, importing more food and improving production efficiency can be effectively implemented. The results of our research described highresolution of agricultural N/P emission to water bodied in Hainan Island and explored the most suitable mitigation strategies for reduction of ANSP emissions at the island scale.

\section{Declarations}

\section{Funding}

The study is sponsored by the National Natural Science Foundation of China (Grant No.52069006, 51569009), the Natural Science Foundation of Hainan (Grant No.421RC489, 419MS019). Author Changqing Ye has received research support from Hainan University.

\section{Competing Interests}

The authors declare that they have no known competing financial interests or personal relationships that could have appeared to influence the work reported in this paper.

\section{Acknowledgement}

We thank Dr Hongwei Zhao for the help on land use data of Hainan Island.

\section{Author contributions}

All authors contributed to the study conception and design.

Xu Liang: Conceptualization, Methodology, Software, Validation, Investigation, Visualization, Writing original draft; Yanhu He: Conceptualization, Resources, Data Curation, Writing - original draft; Lirong Zhu: Resources, Validation; Shijie Fan: Data Curation, Investigation; Yi Zou: Investigation; Changqing Ye: Resources, Investigation, Writing - review and editing, Funding acquisition

\section{Compliance with Ethical Standards}

\section{Ethical Approval}

We declare that we have complied with ethical responsibilities before submitting the manuscript.

\section{Disclosure of potential conflicts of interest}

Our manuscript has not been published before and is not being considered for publication elsewhere. All authors have contributed to the creation of this manuscript for important intellectual content and read and approved the final manuscript. We declare there is no conflict of interest. 


\section{Consent to Participate}

Not applicable

\section{Consent to Publish}

Not applicable

\section{References}

1. Bai Z et al (2016) Nitrogen, Phosphorus, and Potassium Flows through the Manure Management Chain in China. Environ Sci Technol 50(24):13409-13418

2. Chadwick D et al (2015) Improving manure nutrient management towards sustainable agricultural intensification in China. Agric Ecosyst Environ 209:34-46

3. Cheng $\mathrm{J}$ et al (2021) Modeling the sources and retention of phosphorus nutrient in a coastal river system in China using SWAT. J Environ Manage 278:111556

4. Fang $X$ et al (2020) Cumulative impact of anthropogenic nutrient inputs on lagoon ecosystems - A case study of Xincun Lagoon, Hainan, China.. Regional Studies in Marine Science, 35:101213

5. Galloway JN et al (2008) Transformation of the Nitrogen Cycle: Recent Trends, Questions, and Potential Solutions. Science 320(5878):889-892

6. Gu B, Ge Y, Chang SX, Luo W, Chang J (2013) Nitrate in groundwater of China: Sources and driving forces. Glob Environ Change 23(5):1112-1121

7. Han J-C et al (2021) Coupling Bayesian-Monte Carlo simulations with substance flow analysis for efficient pollutant management: A case study of phosphorus flows in China. Resources, Conservation and Recycling, 169: 105550

8. Herbeck LS, Unger D, Wu Y, Jennerjahn TC (2013) Effluent, nutrient and organic matter export from shrimp and fish ponds causing eutrophication in coastal and back-reef waters of NE Hainan, tropical China. Cont Shelf Res 57:92-104

9. Hou $Y$ et al (2018) Changes in nitrogen and phosphorus flows and losses in agricultural systems of three megacities of China, 1990-2014, vol 139. Resources, Conservation and Recycling, pp 64-75

10. Huang J, Xu C-c, Ridoutt BG, Wang X-c, Ren P-a (2017) Nitrogen and phosphorus losses and eutrophication potential associated with fertilizer application to cropland in China. J Clean Prod 159:171-179

11. Kaushal SS et al (2011) Tracking nonpoint source nitrogen pollution in human-impacted watersheds. Environ Sci Technol 45(19):8225-8232

12. Koops JG, Oenema O, Beusichem M (1996) Denitrification in the top and sub soil of grassland on peat soils. Plant Soil 184(1):1-10

13. Li Z et al (2015) Assessment of the AnnAGNPS model in simulating runoff and nutrients in a typical small watershed in the Taihu Lake basin, China. CATENA 133:349-361 
14. Lu X et al (2021) Carbon and nitrogen isotopic compositions of particulate organic matter in the upwelling zone off the east coast of Hainan Island, China. Mar Pollut Bull 167:112349

15. Ma L et al (2010) Modeling Nutrient Flows in the Food Chain of China. J Environ Qual 39(4):12791289

16. Ma L et al (2012) Nitrogen and phosphorus use efficiencies and losses in the food chain in China at regional scales in 1980 and 2005. Sci Total Environ 434:51-61

17. MEEP (2020) Ministry of Environmental Protection, Bulletin of National Environmental Statistics 2017. MEEP, Beijing. [in Chinese].

18. Remund D, Liebisch F, Liniger HP, Heinimann A, Prasuhn V (2021) The origin of sediment and particulate phosphorus inputs into water bodies in the Swiss Midlands - A twenty-year field study of soil erosion. CATENA 203:105290

19. Rodríguez-Gallego $L$ et al (2017) Effects of land use changes on eutrophication indicators in five coastal lagoons of the Southwestern Atlantic Ocean. Estuarine, Coastal and Shelf Science, 188: 116126

20. Salm, Dolfing J, Heinen M, Velthof GL (2007) Estimation of nitrogen losses via denitrification from a heavy clay soil under grass. Agriculture Ecosystems \& Environment 119(3-4):311-319

21. Sun R et al (2020) Effects of land-use change on eco-environmental quality in Hainan Island, China. Ecological Indicators, 109: 105777

22. Velthof GL et al (2009) Integrated Assessment of Nitrogen Losses from Agriculture in EU-27 using MITERRA-EUROPE. J Environ Qual 38(2):402-417

23. Vigouroux $\mathrm{G}$ et al (2021) Trend correlations for coastal eutrophication and its main local and wholesea drivers - Application to the Baltic Sea. Sci Total Environ 779:146367

24. Wang $Y$ et al (2021) Coastal eutrophication in China: Trend, sources, and ecological effects. Harmful Algae: 102058

25. Yan R, Gao J (2021) Key factors affecting discharge, soil erosion, nitrogen and phosphorus exports from agricultural polder. Ecol Model 452:109586

26. Yang B, Liu S-M, Wu Y, Zhang J (2016) Phosphorus speciation and availability in sediments off the eastern coast of Hainan Island, South China Sea. Cont Shelf Res 118:111-127

27. Yu C, Huang X, Chen $\mathrm{H}$ (2019) Managing nitrogen to restore water quality in China. Nature 567(7749):1

28. Zhang C, Rees RM, Ju X (2021) Cropping system design can improve nitrogen use efficiency in intensively managed agriculture. Environ Pollut 280:116967

29. Zhang J, Wang DR, Jennerjahn T, Dsikowitzky L (2013) Land-sea interactions at the east coast of Hainan Island, South China Sea: A synthesis. Cont Shelf Res 57:132-142

30. Zhang P et al (2020a) Spatiotemporal variation, composition of DIN and its contribution to eutrophication in coastal waters adjacent to Hainan Island, China.. Regional Studies in Marine Science, 37:101332 
31. Zhang P, Ruan H, Dai P, Zhao L, Zhang J (2020b) Spatiotemporal river flux and composition of nutrients in response to adjacent coastal water quality in Hainan Island, China.Journal of Hydrology:125293

32. Zhao Z, Qin W, Bai Z, Ma L (2019) Agricultural nitrogen and phosphorus emissions to water and their mitigation options in the Haihe Basin, China. Agric Water Manage 212:262-272

33. Zhou S (2011) Agricultural non-points source (soil runoff) pollution research in Hainan island. Master Thesis, Hainan university

\section{Figures}

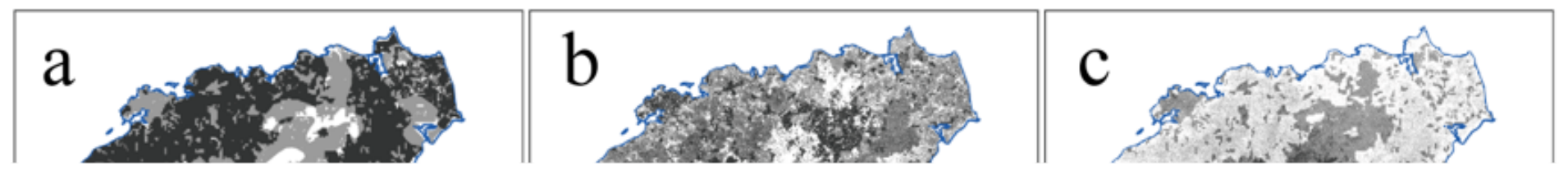

\section{Figure 1}

Distribution of leaching, erosion and runoff loss coefficient of $\mathrm{N}$ and $\mathrm{P}$ in crop system. (a for $\mathrm{N}$ leaching; $\mathrm{b}$ for $\mathrm{N}$ erosion; $\mathrm{C}$ for $\mathrm{N}$ runoff; $\mathrm{d}$ for $\mathrm{P}$ leaching, e for $\mathrm{P}$ erosion; $\mathrm{f}$ for $\mathrm{P}$ runoff.) 


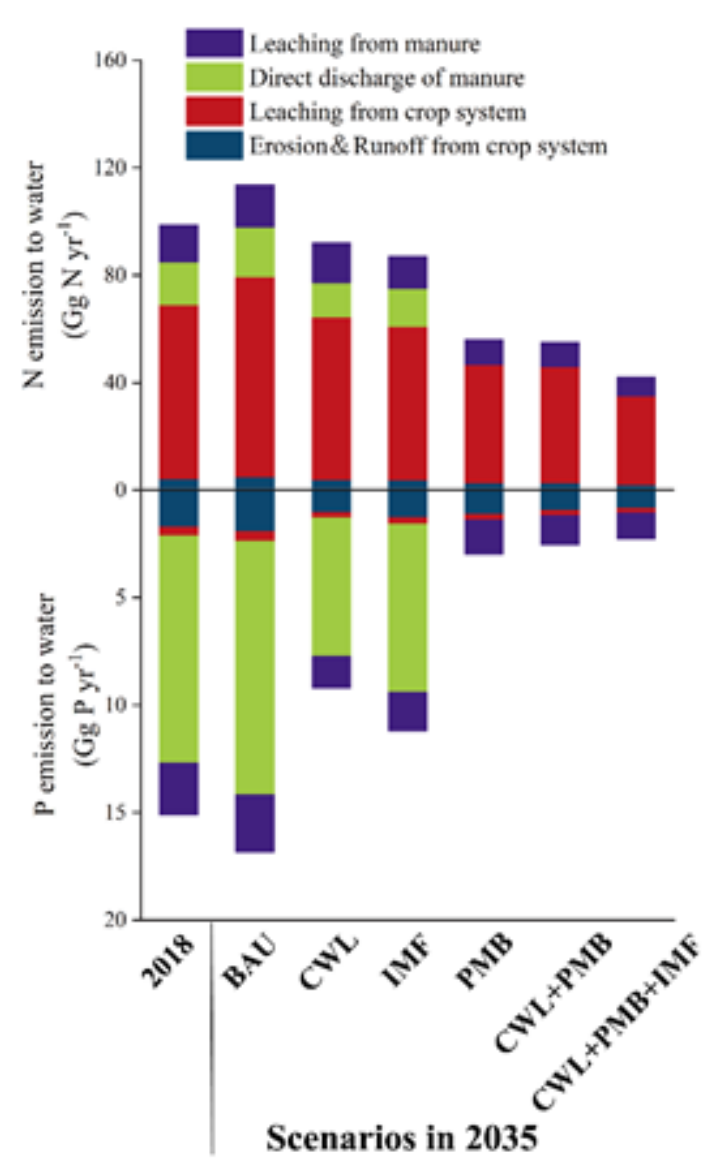

Figure 2

Agricultural N and P emissions to water in the Hainan Island in 2018 and 2035 under the different scenarios. BAU: Business As Usual, IMF: Importing More Food, CWL: Consuming and Wasting Less, PMB: Producing More and Better.

\section{Figure 3}

Spatial distribution of agricultural $\mathrm{N}$ emissions in the basin of Hainan Island in 2018 (Unit: $\mathrm{t} \mathrm{km}^{-2} \mathrm{yr}^{-1}$ ). (a): N emissions to water; (a1): N leaching in crop system; (a2): N erosion \& runoff in crop system; (a3): N leaching from animal manure management chain in animal system; (a4): $\mathrm{N}$ direct discharge from animal manure management chain in animal system. 1: Nandu river; 2: Changhua river; 3: Wanquan river; 4: Lingshui river 5: Zhubi river 6: The west rivers 7: Beimen river 8: Ningyuan river 9: Wenlan river10: The north rivers11: Tengqiao river; 12: Wanglou river; 13: Taiyang river; 14: Chun river; 15: Wenjiao river; 16 : Luodai river; 17: Sanya river; 18: Shibi river; 19: Jiuqu river; 20: Zhuxi river; 21: Wenchang river; 22 : Yanzhou river; 23: Northeast rivers; 24: Jiangdong district; 25: Longshou river; 26: Longwei river. 
Spatial distribution of agricultural $\mathrm{P}$ emissions in the basin of Hainan Island in 2018 (Unit: $\mathrm{t} \mathrm{km}^{-2} \mathrm{yr}^{-1}$ ). (a): P emissions to water; (b1): P leaching in crop system; (b2): P erosion \& runoff in crop system; (b3): P leaching from animal manure management chain in animal system; (b4): P direct discharge from animal manure management chain in animal system. 1: Nandu river; 2: Changhua river; 3: Wanquan river; 4: Lingshui river 5: Zhubi river 6: The west rivers 7: Beimen river 8: Ningyuan river 9: Wenlan river10: The north rivers11: Tengqiao river; 12: Wanglou river; 13: Taiyang river; 14: Chun river; 15: Wenjiao river; 16 : Luodai river; 17: Sanya river; 18: Shibi river; 19: Jiuqu river; 20: Zhuxi river; 21: Wenchang river; 22: Yanzhou river; 23: Northeast rivers; 24: Jiangdong district; 25: Longshou river; 26: Longwei river.

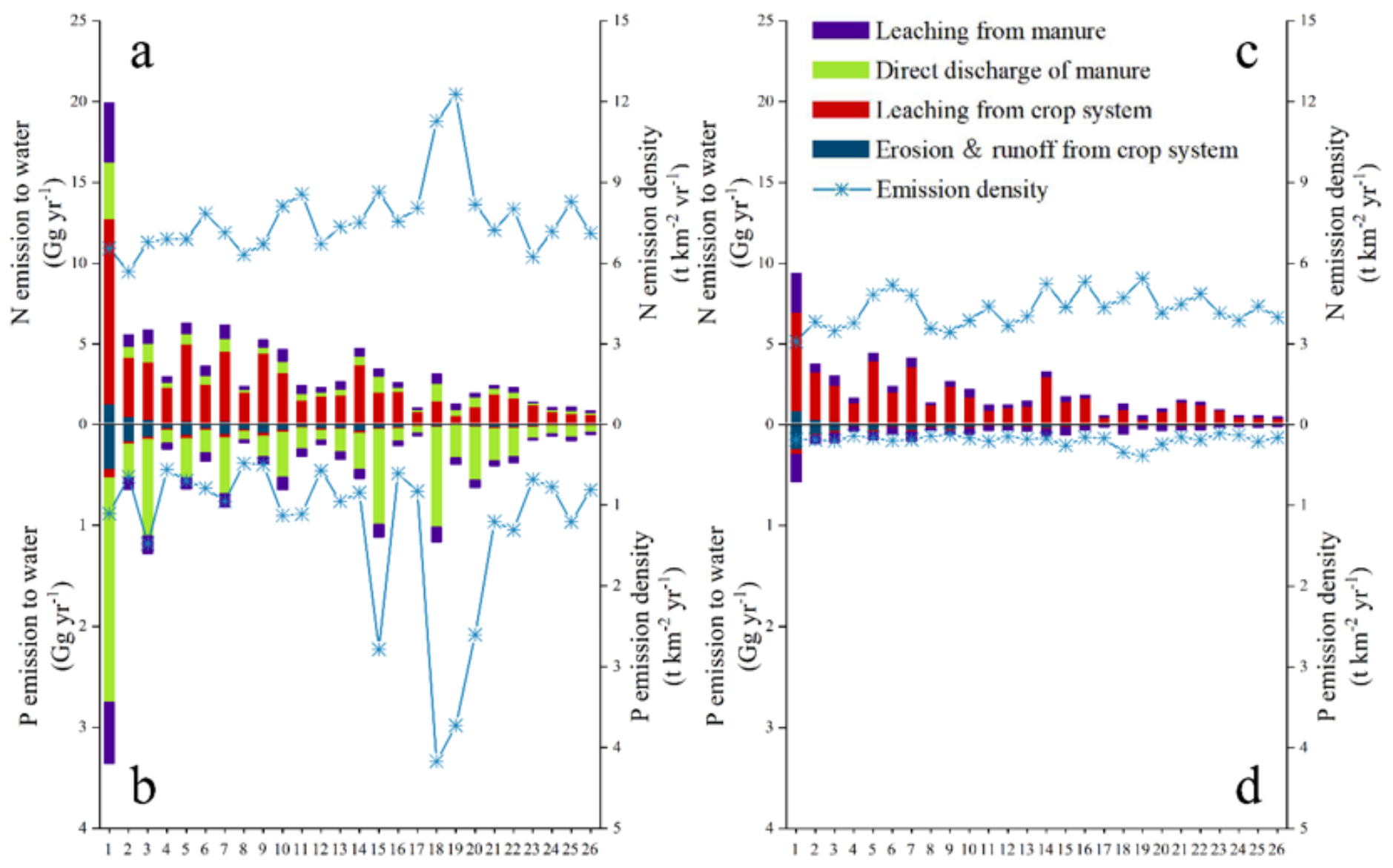

Figure 5

Agricultural $\mathrm{N}$ and $\mathrm{P}$ emissions to water and emission density in the sub-basins in $2018(\mathrm{a}, \mathrm{b})$ and 2035 under the PMB+CWL scenario $(c, d)$

Figure 6

Zones of $\mathrm{N}$ and $\mathrm{P}$ emissions in 2018 in Hainan Island (LL: Low N and P emission; LH: Low N emission and high P emission; HL: High N emission and low P emission; $\mathrm{HH}$ : High N and P emission)1: Nandu river; 2: Changhua river; 3: Wanquan river; 4: Lingshui river 5: Zhubi river 6: The west rivers 7: Beimen river 8: 
Ningyuan river 9: Wenlan river10: The north rivers11: Tengqiao river; 12: Wanglou river; 13: Taiyang river; 14: Chun river; 15: Wenjiao river; 16: Luodai river; 17: Sanya river; 18: Shibi river; 19: Jiuqu river; 20: Zhuxi river; 21: Wenchang river; 22: Yanzhou river; 23: Northeast rivers; 24: Jiangdong district; 25: Longshou river; 26: Longwei river.

\section{Figure 7}

Relationships between natural factors (temperature, precipitation, elevation, slope, soil texture), anthropogenic factors (rural income, population density) and N, P emissions to water. Red dots represent $\mathrm{N}$, blue dots represent $\mathrm{P}$, the data were based on towns-level.

\section{Figure 8}

Relationships between planting sturcture, livestock density, slope and soil texture and $\mathrm{N}$ emission to water on the basis of towns-level data in the plain and hill regions, respectively.

\section{Figure 9}

Relationships between planting sturcture, livestock density, slope and soil texture and P emission to water on the basis of towns-level data in the plain and hill regions, respectively.

\section{Supplementary Files}

This is a list of supplementary files associated with this preprint. Click to download.

- Supplementallnformation.docx 